\title{
Vitamin C Improves the Health Span of Animal Models of Werner Syndrome
}

\author{
Michel Lebel* \\ Centre de recherche du CHU de Québec, Faculty of Medicine, Université Laval, Quebec City, Quebec, Canada
}

\section{Article Info}

\section{Article Notes}

Received: May 20, 2016

Accepted: June 06, 2016

\section{*Correspondence:}

Dr. Michel Lebel, Ph.D.

Centre de recherche du CHU de Québec,

Centre Hospitalier de l'Université Laval,

2705 Laurier Boulevard, Québec City,

Québec, G1V 4G2, Canada,

E-mail: michel.lebel@crchudequebec.ulaval.ca

(c) 2016 Lebel M. This article is distributed under the terms of the Creative Commons Attribution 4.0 International License.

\section{Keywords}

Werner syndrome

Aging

Vitamin C

Metabolomic

Inflammation

Antioxidant

\begin{abstract}
Werner syndrome (WS) is a rare autosomal recessive disorder characterized by a pro-oxidant/pro-inflammatory status, genomic instability, and by the premature onset of several age-associated diseases. The protein defective in WS patients (WRN) is a helicase/exonuclease involved in DNA replication, repair, and transcription. This review focuses on the beneficial impact of vitamin C treatment in mutant mouse and worm models of WS with an emphasis on serum metabolomic and cytokinome profiles in Wrn mutant mice. Vitamin $C$ normalizes the health and life span of these mutant animals. More importantly, our recent results indicate that it will be possible to follow the beneficial impact of vitamin $\mathrm{C}$ at a systemic level by monitoring specific serum metabolites and inflammatory cytokines in a longitudinal study involving WS patients.
\end{abstract}

\section{Main text}

Werner Syndrome (WS; MIM\# 277700) is an autosomal recessive disorder characterized by genomic instability and the premature onset of a number of age-related diseases including ocular cataracts, dyslipidemia, diabetes mellitus, osteoporosis, atherosclerosis, and cancer $^{1-3}$. The gene responsible for WS $(W R N)$ was identified by positional cloning ${ }^{4}$ and its product contains an evolutionary conserved RecQ DNA helicase consensus domain ${ }^{4-6}$. The protein also has a $3^{\prime}-5^{\prime}$ exonuclease activity ${ }^{7-9}$. WS is a rare disorder worldwide. However, the frequency of WS can be highly prevalent in certain regional populations showing high degrees of consanguinity. For example, the frequency of carriers has been estimated to be as high as $1 / 150$ to $1 / 200$ in several prefectures of Japan with a prevalence of homozygotes of $\sim$ three in one million newborns (see http://atlasgeneticsoncology.org/Kprones/WernerID10017. $\mathrm{htm}$ ). More than eighty distinct mutations potentially inactivating the WRN protein have been described in WS patients to date based on The International Registry of Werner Syndrome; Department of Pathology, University of Washington, Seattle, WA, USA (www. wernersyndrome.org). These mutations include missense and nonsense substitutions, frame shifts and premature translation termination mutations, deletions and insertions. All these mutations are believed to disrupt the normal function of the protein or to cause a truncation of the protein such that it cannot localize to the nucleus, the normal site of WRN protein action. Accumulating evidences indicate that WRN is involved in DNA replication, DNA repair, and telomere maintenance ${ }^{10-18}$. WRN interacts with several proteins 
important for homologous recombination, nonhomologous recombination, and long-patch base excision repair pathways ${ }^{12,14,17,19-24}$. In addition to defects in DNA replication and repair, alterations of gene expression at the RNA level have also been observed in WS cells implicating WRN in some aspects of transcription as well ${ }^{25-27}$. Accordingly, mass spectrometry analysis of an immunoprecipitated tagged WRN protein revealed the presence of several transcription factors (such as SAFB1, Scaffold Attachment Factor B1) ${ }^{28}$ and two subunits of the RNA polymerase II machinery (POLR2A and POLR2B) ${ }^{19}$. However, such interactions with WRN were lost upon nuclease treatments of the lysates prior to the immunoprecipitation step. These results suggest that the interaction between WRN and the RNA polymerase II machinery requires nucleic acids. In addition, the WRN protein modulates the expression of genes containing G-quadruplex DNA structures, a family of non-canonical nucleic acid structures formed by certain G-rich sequences at several chromosomal sites in WS fibroblasts ${ }^{26,27}$. However, WS cells contain several chromosomal rearrangements that may affect gene expression and the interpretation of the data. To avoid using WS fibroblasts from patients that accumulated DNA rearrangements with time, we depleted WRN protein levels in normal human fibroblasts for a short period of time (48 hours) with small interfering RNAs specific for the WRN mRNA to perform expression-profiling studies ${ }^{29}$. We determined that such WRN-depleted cells did not have time to accumulate mutations within 48 hours but exhibited increased oxidative stress. Oxidative stress is believed to exacerbate several age-related diseases ${ }^{30}$. More importantly, our microarray analyses determined that a short-term knock down of WRN was sufficient to induce an expression profile resembling the one obtained with fibroblasts derived from old individuals ${ }^{29}$. Thus, besides the already known impact of WRN on DNA replication, DNA repair, the p21/p53 pathway and cell cycle, gene set enrichment analyses of our microarray data uncovered significant impact of WRN levels on the expression of genes involved in adipocyte differentiation, oxidative stress, and inflammatory responses ${ }^{29}$. Remarkably, several defects observed in WS patients are reminiscent of a chronic inflammatory metabolic syndrome, which can also be observed in the general aging population ${ }^{31}$. Metabolic syndrome afflicts up to half the population of western countries and is considered an age-related proinflammatory lipid disorder ${ }^{32}$. Accordingly, increased oxidative stress has been described for WS subjects in addition to the abnormal metabolic phenotypes such as enhanced intra-abdominal visceral fat accumulation or non-alcoholic hepatic steatosis ${ }^{33-36}$. Finally, cytokine analyses of the serum of WS patients indicated abnormal elevation of several inflammatory cytokines or interleukins like IL-4, IL-6, or IL-10 in addition to an abnormal increase of the cardiovascular risk factor plasminogen activator inhibitor 1 (PAI-1) $)^{37,38}$. Several of these cytokines are collectively referred to as the senescence-associated secretory phenotype and are important hallmarks of aging. Interestingly, this senescence-associated secretory phenotype is suppressed by reprogramming WS fibroblasts to generate WS induced-pluripotent stem cells upon transduction of the Yamanaka factors (OCT3/4, SOX2, KLF4 , and c-myc) ${ }^{39}$.

A mouse model containing a deletion of part of the helicase domain was generated to understand the molecular basis of the premature aging phenotype in $\mathrm{WS}^{40}$. This mutant mouse (referred as $W r n^{\Delta h e l / \Delta h e l}$ ) synthesizes a stable mutant protein that has no helicase and exonuclease activities $^{41}$. Interestingly, the metabolic and cytokine profiles of $W r n^{\Delta h e l / \Delta h e l}$ mice is different from age-matched wild type mice or the mutant Wrn null mice that do not

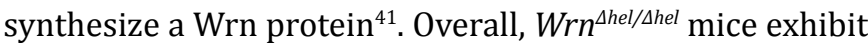
a marked dyslipidemia, show evidence of a low but chronic systemic inflammation, and a $17-22 \%$ reduction in mean life span compared to wild type and Wrn null mice. The $W r n^{\Delta h e l / \Delta h e l}$ mouse model phenocopies several other aspects of the human WS such as hyperglycemia and insulin resistance, elevated blood hyaluronic acid, increased serum IL-10 and PAI-1, hepatic steatosis, aortic stenosis, cardiac fibrosis, and several types of cancer ${ }^{42-45}$. Importantly, we found that the Wrn helicase mutant protein is mislocalized to the cytoplasm in tissues of $W r n^{\Delta h e l / \Delta h e l}$ mice $^{41}$. In addition to the loss of Wrn activites in the nucleus, this cytoplasmic mislocalization affects the normal function of several organelles, including the peroxisomes, the endoplasmic reticulum, and the autophagosomes, leading potentially to

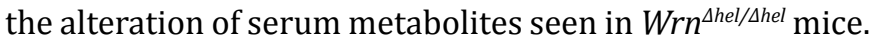
Such alterations may be the precursor of molecular events responsible for the age-related changes observed in older $W r n^{\Delta h e l / \Delta h e l}$ mice. Of relevance to this mouse work, a recent report indicated that WS patients with a nonsense mutation at position 1256 of the human WRN protein synthesized a stable truncated protein localized in the cytoplasm of their cells ${ }^{46}$. These patients exhibited type 2 diabetes, cataracts, hypercholesterolemia, short stature, bird-like facies, skin ulcers on the lower limbs, osteoporosis, and arterial atherosclerosis. A survey of different WS derived cells with different mutations will be required with the appropriate antibodies to assess the impact of abnormal WRN protein in such cells. It will be important to determine whether the phenotype of human WS cells expressing a detectable mislocalized truncated WRN protein is more severe than WS cells with no measurable level of WRN protein.

One advantage of using animal models is the possibility of modifying their diet in a controlled laboratory setting. Interestingly, $W r n^{\Delta h e l / \Delta h e l}$ mice show a decrease in serum glutathione (GSH) level and an increase in serum vitamin 
C level ${ }^{47}$. Notably, WS patients also exhibit an imbalance in plasma GSH level and an increase in serum ascorbic acid (vitamin $\mathrm{C}$ ), suggesting a pro-oxidant status in such individuals ${ }^{33}$. The increase in vitamin C levels in $W^{\Delta r}{ }^{\Delta h e l / \Delta h e l}$ mice may be due to a response to the abnormal redox status in such animals inferred by the elevated oxidative DNA damage, the augmented lipid peroxidation and reactive oxygen species levels in several tissues of these mutant mice $^{43}$, 47. Importantly, supplementation of $\mathrm{Wrn}^{\Delta h e l / \Delta h e l}$ mice with $0.4 \%$ vitamin C (weight/volume) in drinking water reversed all the phenotypes observed in $W r n^{\Delta h e l / \Delta h e l}$ mice and increased the mean life span of these animals to a normal wild type life $\operatorname{span}^{47}$. Such a complete reversal of the phenotypes observed in $W r n^{\Delta h e l / \Delta h e l}$ mice was not obtained with other known antioxidants like resveratrol or catechin $^{43,48}$. It is important to mention that vitamin $\mathrm{C}$ is not only a soluble antioxidant but also an important co-factor for hydrolase and monooxygenase enzymes involved in the synthesis of collagen, carnitine, and neurotransmitters ${ }^{49}$. Carnitine is required for the transport and transfer of fatty acids into mitochondria where it can be used for energy production. Vitamin $\mathrm{C}$ is also necessary for the transformation of cholesterol to bile acids as it modulates microsomal hydroxylation reactions in the liver ${ }^{49}$. In addition, vitamin $\mathrm{C}$ regulates the active levels of several transcription factors like HIF1 $\alpha$ (Hypoxia induced factor $1 \alpha$ ) or NF-KB (a factor that can modulate inflammatory responses) ${ }^{50,51}$. Accordingly, we observed that vitamin $\mathrm{C}$ treatment reversed the abnormal high levels of active HIF1 $\alpha$ and NF- $\kappa B$ found in the liver of $W r n^{\Delta h e l / \Delta h e l}$ mice $^{47}$. Vitamin C is also important for the activities of enzymes involved in the oxidative protein folding reactions in the endoplasmic reticulum ${ }^{52}$. Noticeably, we found that the mislocalization of the Wrn helicase mutant protein in the endoplasmic reticulum fraction from liver tissues increased oxidative stress in that cellular compartment even in younger fourmonth old mice before they exhibit hepatic steatosis, cardiac fibrosis, or cancer. Thus, although younger $W_{r n} n^{\text {shel/shel }}$ mice did not exhibit a pro-oxidant status at the systemic level, they did show oxidative stress at the sub-cellular level in tissues. Vitamin $C$ treatment reversed this stress in the endoplasmic reticulum of $W_{r n} n^{\text {¿hel/ } / \Delta h e l}$ mice ${ }^{45}$.

We have evidence that vitamin $C$ is not only efficient in reversing the age-related phenotypes observed in $W r n^{\Delta h e l / \Delta h e l}$ mice, but it is also efficient in reversing aging in the worm Caenorhabditis elegans bearing a nonfunctional $w r n-1$ DNA helicase ortholog ${ }^{53}$. The longevity of wrn-1 mutant worms is reduced compared to wild type worms when grown at $25^{\circ} \mathrm{C}$. The median life span of vitamin $\mathrm{C}$ treated wrn-1 mutant worms was significantly increased by $26 \%$ compared to untreated wrn-1 mutant animals and was comparable to the normal median life span of wild type worms.
Altogether, the results obtained with both worms and mice support the hypothesis that vitamin $C$ treatment may improve the health and/or life span of very different species bearing a debilitating mutation in the WRN gene ortholog. Thus, a long-term vitamin $C$ supplementation could have beneficial effects for human patients with WS. A major advantage of using vitamin $\mathrm{C}$ as a potential treatment for WS is the wide range of concentrations that can be used without toxic effect in humans. Another advantage is the possibility of following the impact of vitamin $C$ treatment in patients with WS by simply monitoring several metabolites and secreted factors in their serum such as specific lipids, glucose, PAI-1, IL-6, or IL-10 ${ }^{37,38}$. Indeed, vitamin $\mathrm{C}$ treatment normalized the serum cardiometabolic and inflammatory profiles of $W_{r n} n^{\text {thel/ } \Delta h e l}$ mice $^{45}$. We hypothesize that similar results could be obtained with WS patients. Of interest, a recent case study indicated that the lipidsoluble antioxidant molecule astaxanthin improved the nonalcoholic fatty liver disease of WS patients with diabetes mellitus ${ }^{54}$. In addition, the reduction of oxidative stress observed in WS fibroblasts alleviates their abnormal in vitro morphological phenotype ${ }^{55}$. Importantly, vitamin C not only regenerates GSH (a natural anti-oxidant) in the body, but it is also capable of recycling the lipid-soluble vitamin $\mathrm{E}^{56}$ providing potentially additional beneficial effect. Thus, it should be possible to perform a longitudinal study by simply examining the systemic inflammatory and oxidant status in vitamin C treated WS patients by means of a straightforward clinical time-course noninvasive blood sampling protocol.

\section{Acknowledgement}

M.L. work is supported by a grant from the Canadian Institutes of Health Research (grant number MOP-67153).

\section{References}

1. Oshima J, Sidorova JM, Monnat RJ, Jr. Werner syndrome: Clinical features, pathogenesis and potential therapeutic interventions. Ageing research reviews 2016; doi: 10.1016/j.arr.2016.03.002.

2. Epstein CJ, Martin GM, Schultz AL, Motulsky AG. Werner's syndrome a review of its symptomatology, natural history, pathologic features, genetics and relationship to the natural aging process. Medicine (Baltimore). 1966; 45:177-221.

3. Lauper JM, Krause A, Vaughan TL, Monnat RJ, Jr.. Spectrum and risk of neoplasia in Werner syndrome: a systematic review. PloS one. 2013; 8:e59709.

4. Yu CE, Oshima J, Fu YH, Wijsman EM, Hisama F, Alisch R, et al. Positional cloning of the Werner's syndrome gene. Science. 1996; 272:258-262.

5. Umezu K, Nakayama K, Nakayama H. Escherichia coli RecQ protein is a DNA helicase. Proceedings of the National Academy of Sciences of the United States of America. 1990; 87:5363-5367

6. Gray MD, Shen JC, Kamath-Loeb AS, Blank A, Sopher BL, Martin GM, et al. The Werner syndrome protein is a DNA helicase. Nature genetics. 1997; 17:100-103

7. Shen JC, Gray MD, Oshima J, Kamath-Loeb AS, Fry M, Loeb LA. Werner syndrome protein. I. DNA helicase and dna exonuclease reside on 
the same polypeptide. The Journal of biological chemistry. 1998 273:34139-34144

8. Kamath-Loeb AS, Shen JC, Loeb LA, Fry M. Werner syndrome protein II. Characterization of the integral 3' --> 5' DNA exonuclease. The Journal of biological chemistry. 1998; 273:34145-34150

9. Huang S, Li B, Gray MD, Oshima J, Mian IS, Campisi J. The premature ageing syndrome protein, WRN, is a $3^{\prime}-->5^{\prime}$ exonuclease. Nature genetics. 1998; 20:114-116

10. Su F, Mukherjee S, Yang Y, Mori E, Bhattacharya S, Kobayashi J, et al. Nonenzymatic role for WRN in preserving nascent DNA strands after replication stress. Cell reports. 2014; 9:1387-1401

11. Basile G, Leuzzi G, Pichierri P, Franchitto A. Checkpoint-dependent and independent roles of the Werner syndrome protein in preserving genome integrity in response to mild replication stress. Nucleic acids research. 2014; 42:12628-12639

12. Cooper MP, Machwe A, Orren DK, Brosh RM, Ramsden D, Bohr VA. Ku complex interacts with and stimulates the Werner protein. Genes Dev. 2000; $14: 907-912$

13. Crabbe L, Verdun RE, Haggblom CI, Karlseder J. Defective telomere lagging strand synthesis in cells lacking WRN helicase activity. Science. 2004; 306:1951-1953

14. Saintigny Y, Makienko K, Swanson C, Emond MJ, Monnat RJ, Jr. Homologous recombination resolution defect in werner syndrome Mol Cell Biol. 2002; 22:6971-6978

15. Shen JC, Loeb LA. The Werner syndrome gene: the molecular basis of RecQ helicase-deficiency diseases. Trends Genet. 2000; 16:213-220

16. Opresko PL, Otterlei M, Graakjaer J, Bruheim P, Dawut L, Kolvraa S, et al. The Werner syndrome helicase and exonuclease cooperate to resolve telomeric D loops in a manner regulated by TRF1 and TRF2. Molecular cell. 2004; 14:763-774

17. Kusumoto-Matsuo R, Ghosh D, Karmakar P, May A, Ramsden D, Bohr VA. Serines 440 and 467 in the Werner syndrome protein are phosphorylated by DNA-PK and affects its dynamics in response to DNA double strand breaks. Aging. 2014; 6:70-81

18. Gocha AR, Acharya S, Groden J. WRN loss induces switching of telomerase-independent mechanisms of telomere elongation, PloS one. 2014; 9:e93991

19. Lachapelle S, Gagne JP, Garand C, Desbiens M, Coulombe Y, Bohr VA, et al. Proteome-wide identification of WRN-interacting proteins in untreated and nuclease-treated samples. Journal of proteome research. 2011; 10:1216-1227

20. Prince PR, Emond MJ, Monnat RJ. Loss of Werner syndrome protein function promotes aberrant mitotic recombination. Genes Dev. 2001; 15:933-938

21. Constantinou A, Tarsounas M, Karow JK, Brosh RM, Bohr VA, Hickson ID, et al. Werner's syndrome protein (WRN) migrates Holliday junctions and co-localizes with RPA upon replication arrest. EMBO reports. 2000; $1: 80-84$

22. Li B, Comai L: Functional interaction between $\mathrm{Ku}$ and the werner syndrome protein in DNA end processing. The Journal of biological chemistry. 2000; 275:28349-28352

23. Harrigan JA, Wilson DM, 3rd, Prasad R, Opresko PL, Beck G, May A, et al. The Werner syndrome protein operates in base excision repair and cooperates with DNA polymerase beta. Nucleic acids research. 2006; $34: 745-754$

24. Sturzenegger A, Burdova K, Kanagaraj R, Levikova M, Pinto C, Cejka $\mathrm{P}$, et al. DNA2 cooperates with the WRN and BLM RecQ helicases to mediate long-range DNA end resection in human cells. The Journal of biological chemistry. 2014; 289:27314-27326

25. Balajee AS, Machwe A, May A, Gray MD, Oshima J, Martin GM, et al.
The Werner syndrome protein is involved in RNA polymerase II transcription. Mol Biol Cell. 1999; 10:2655-2668

26. Johnson JE, Cao K, Ryvkin P, Wang LS, Johnson FB. Altered gene expression in the Werner and Bloom syndromes is associated with sequences having G-quadruplex forming potential. Nucleic acids research; 2010; 38:1114-1122

27. Tang W, Robles AI, Beyer RP, Gray LT, Nguyen GH, Oshima J, et al. The Werner syndrome RECQ helicase targets G4 DNA in human cells to modulate transcription. Human molecular genetics. 2016.

28. Lachapelle S, Oesterreich S, Lebel M. The Werner syndrome helicase protein is required for cell proliferation, immortalization, and tumorigenesis in Scaffold attachment factor B1 deficient mice. Aging. $2011 ; 3: 277-290$

29. Turaga RV, Paquet ER, Sild M, Vignard J, Garand C, Johnson FB, et al. The Werner syndrome protein affects the expression of genes involved in adipogenesis and inflammation in addition to cell cycle and DNA damage responses. Cell Cycle. 2009; 8:2080-2092

30. Pallardo FV, Lloret A, Lebel M, d'Ischia M, Cogger VC, Le Couteur DG, et al. Mitochondrial dysfunction in some oxidative stress-related genetic diseases: Ataxia-Telangiectasia, Down Syndrome, Fanconi Anaemia and Werner Syndrome. Biogerontology. 2010; 11:401-419

31. Hotamisligil GS. Inflammation and metabolic disorders.Nature. 2006; 444:860-867

32.Eckel RH, Grundy SM, Zimmet PZ. The metabolic syndrome. Lancet. $2005 ; 365: 1415-1428$

33.Pagano G, Zatterale A, Degan P, d'Ischia M, Kelly FJ, Pallardo FV, et al. In vivo prooxidant state in Werner syndrome (WS): results from three WS patients and two WS heterozygotes. Free radical research. 2005; 39:529-533

34.Pagano G, Zatterale A, Degan P, d'Ischia M, Kelly FJ, Pallardo FV, et al. Multiple involvement of oxidative stress in Werner syndrome phenotype. Biogerontology. 2005; 6:233-243

35. Mori S, Yokote K, Morisaki N, Saito Y, Yoshida S. Inheritable abnormal lipoprotein metabolism in Werner's syndrome similar to familial hypercholesterolaemia. Eur J Clin Invest. 1990; 20:137-142

36. Hashizume H, Sato K, Takagi H, Kanda D, Kashihara T, Kiso S, et al. Werner syndrome as a possible cause of non-alcoholic steatohepatitis. Journal of clinical pathology. 2009; 62:1043-1045

37. Goto M, Hayata K, Chiba J, Matsuura M, Iwaki-Egawa S, Watanabe Y. Multiplex cytokine analysis of Werner syndrome, Intractable \& rare diseases research. 2015; 4:190-197

38. Murano S, Nakazawa A, Saito I, Masuda M, Morisaki N, Akikusa B, et al. Increased blood plasminogen activator inhibitor-1 and intercellular adhesion molecule-1 as possible risk factors of atherosclerosis in Werner syndrome. Gerontology. 1997; 1:43-52

39. Shimamoto A, Kagawa H, Zensho K, Sera Y, Kazuki Y, Osaki M, et al. Reprogramming suppresses premature senescence phenotypes of Werner syndrome cells and maintains chromosomal stability over long-term culture. PloS one. 2014; 9:e112900

40.Lebel M, Leder P. A deletion within the murine Werner syndrome helicase induces sensitivity to inhibitors of topoisomerase and loss of cellular proliferative capacity. Proceedings of the National Academy of Sciences of the United States of America. 1998; 95:13097-13102

41. Aumailley L, Garand C, Dubois MJ, Johnson FB, Marette A, Lebel M. Metabolic and Phenotypic Differences between Mice Producing a Werner Syndrome Helicase Mutant Protein and Wrn Null Mice. PloS one. 2015; 10:e0140292

42. Lebel M, Cardiff RD, Leder P. Tumorigenic effect of nonfunctional p53 or p21 in mice mutant in the Werner syndrome helicase, Cancer research. 2001; 61:1816-1819 
43. Labbe A, Garand C, Cogger VC, Paquet ER, Desbiens M, Le Couteur DG, et al. Resveratrol improves insulin resistance hyperglycemia and hepatosteatosis but not hypertriglyceridemia, inflammation, and life span in a mouse model for Werner syndrome, The journals of gerontology Series A. Biological sciences and medical sciences. 2011; 66:264-278.

44. Massip L, Garand C, Turaga RV, Deschenes F, Thorin E, Lebel M. Increased insulin, triglycerides, reactive oxygen species, and cardiac fibrosis in mice with a mutation in the helicase domain of the Werner syndrome gene homologue. Experimental gerontology. 2006; 41:157-168.

45.Aumailley L, Dubois MJ, Garand C, Marette A, Lebel M. Impact of vitamin $\mathrm{C}$ on the cardiometabolic and inflammatory profiles of mice lacking a functional Werner syndrome protein helicase. Experimental gerontology. 2015; 72:192-203

46.Agrelo R, Sutz MA, Setien F, Aldunate F, Esteller M, Da Costa V, et al. A novel Werner Syndrome mutation: pharmacological treatment by read-through of nonsense mutations and epigenetic therapies. Epigenetics. 2015; 10:329-341

47. Massip L, Garand C, Paquet ER, Cogger VC, O’Reilly JN, Tworek L, et al. Vitamin $C$ restores healthy aging in a mouse model for Werner syndrome. FASEB journal : official publication of the Federation of American Societies for Experimental Biology. 2010; 24:158-172.

48. Lebel M, Massip L, Garand C, Thorin E. Ascorbate improves metabolic abnormalities in Wrn mutant mice but not the free radical scavenger catechin. Annals of the New York Academy of Sciences. 2010; 1197:40-44

49. Naidu KA. Vitamin C in human health and disease is still a mystery? An overview. Nutrition journa. 2003; 2:7
50.Labbe A, Lafleur VN, Patten DA, Robitaille GA, Garand C, Lamalice L, et al. The Werner syndrome gene product (WRN): a repressor of hypoxia-inducible factor-1 activity. Experimental cell research. 2012; 318:1620-1632

51.Carcamo JM, Pedraza A, Borquez-Ojeda O, Zhang B, Sanchez R, Golde DW. Vitamin $C$ is a kinase inhibitor: dehydroascorbic acid inhibits IkappaBalpha kinase beta. Mol Cell Biol. 2004; 24:6645-6652

52. Banhegyi G, Benedetti A, Margittai E, Marcolongo P, Fulceri R, Nemeth $\mathrm{CE}$, et al. Subcellular compartmentation of ascorbate and its variation in disease states. Biochimica et biophysica acta. 2014; 1843:19091916

53. Dallaire A, Proulx S, Simard MJ, Lebel M. Expression profile of Caenorhabditis elegans mutant for the Werner syndrome gene ortholog reveals the impact of vitamin $\mathrm{C}$ on development to increase life span. BMC genomics. 2014; 15:940

54. Takemoto M, Yamaga M, Furuichi Y, Yokote K. Astaxanthin Improves Nonalcoholic Fatty Liver Disease in Werner Syndrome with Diabetes Mellitus. Journal of the American Geriatrics Society 2015; 63:12711273

55. Talaei F, van Praag VM, Henning RH. Hydrogen sulfide restores a normal morphological phenotype in Werner syndrome fibroblasts, attenuates oxidative damage and modulates mTOR pathway. Pharmacological research. 2013; 74:34-44

56.Goszcz K, Deakin SJ, Duthie GG, Stewart D, Leslie SJ, Megson IL. Antioxidants in Cardiovascular Therapy: Panacea or False Hope? Frontiers in cardiovascular medicine. 2015; 2:29 